\title{
The Paterson-Kelly Syndrome
}

\author{
ALLAN JACOBS,* M.D.; G. S. KILPATRICK, $\dagger$ M.D., M.R.C.P.ED.
}

Brit. med. F., 1964, 2, 79-82

Dysphagia localized to the post-cricoid region occurring mainly in middle-aged women was first fully described in the papers of Paterson (1919) and Kelly (1919). Kelly noted an association with anaemia, superficial glossitis, and angular stomatitis, while Paterson remarked on "the not infrequent supervention of malignant disease at the mouth of the gullet." Vinson (1922) observed the development of hypothyroidism in some patients. Moersch and Conner (1926) studied 65 patients with the syndrome and found the majority to have a hypochromic anaemia: achlorhydria was demonstrated in 8 of the 10 patients tested. Witts (1931) confirmed these findings in a smaller group of patients, and found that although the anaemia responded to iron there was a tendency for it to relapse. Waldenström and Hallen (1938) showed that the syndrome could occur with iron deficiency unaccompanied by anaemia, and the term "sideropenic dysphagia" was coined.

Although it is commonly held that iron deficiency is the basic cause of post-cricoid dysphagia in middle-aged women (Ahlbom, 1936 ; Smiley, McDowell, and Costello, 1963) proof of a cause-and-effect relationship has not been obtained. Such a relationship has been doubted by several authors (Kirchenberger and Flett, 1946 ; Wynder and Fryer, 1958; Jacobs, 1963), and we prefer to use the name Paterson-Kelly syndrome until such time as the aetiology and pathology of the condition have been clarified. The occurrence of this syndrome, together with its malignant sequelae in cases of pernicious anaemia (Jacobs, 1962), stimulated the present investigation.

\section{Present Series}

We have been fortunate in being able to see a large number of patients with the Paterson-Kelly syndrome. This is mainly owing to the sustained interest shown by the staff of the Cardiff Royal Infirmary over the past 40 years, which has resulted in cases being referred here from all parts of South Wales. A clinical and haematological examination has been carried out on 55 patients seen here between May 1962 and April 1963. It is shown that in addition to iron deficiency and gastric atrophy many of them have features of pernicious anaemia.

Patients were selected for study because they had difficulty in swallowing specifically localized to the post-cricoid region ( 52 cases) or because of the presence of a symptomless postcricoid web ( 3 cases). Thirty-six patients were under the care of ear, nose, and throat surgeons because of dysphagia, and in 16 the symptom was elicited in the course of investigation for other conditions (anaemia 14 cases, hiatus hernia 1 case, and senile cataract 1 case).

This group of hospital patients is a selected one and may not fully represent the syndrome as it exists in the general population.

History and Clinical Examination.-Each patient was interviewed and examined by one of us (G.S. K.) and a barium swallow examination carried out. Oesophagoscopy was performed in 38 patients.

\footnotetext{
- Institute of Pathology, Welsh National School of Medicine, Cardiff Royal Infirmary. t Medical Unit, Welsh National School of Medicine, Cardiff Royal
Infirmary.
}

Blood Examination.-Standard haematological methods were used (Dacie, 1956).

Serum iron and total iron-binding capacity were estimated by the method of Ramsay (1957), using $\alpha^{\prime} \alpha^{\prime}$-dipyridyl.

Serum vitamin $B_{12}$ was assayed, using Euglena gracilis.

Tubeless gastric analysis was carried out by a variation of the method described by Correia and de Moura (1963). This technique was used because some of the patients were unable to swallow a tube and many could have been intubated only with great difficulty and discomfort. Maximum stimulation of the gastric mucosa was achieved with histamine. Histamine acid phosphate $0.04 \mathrm{mg}$. $/ \mathrm{kg}$. body weight was injected subcutaneously at the same time as the azuresin granules were given by mouth. Anthisan (mepyramine maleate) $100 \mathrm{mg}$. was given by intramuscular injection 30 minutes before this to prevent untoward effects of the histamine. Achlorhydria was diagnosed when less than $3 \mathrm{mg}$. of the dye was excreted in the urine in the test period. Correia and de Moura found that this test could be relied on to detect achlorhydria. Nonexcretion of the dye when acid was present in the stomach ( $4 \%$ of their group) was associated with a low acid output.

Schilling Test.-A modification of the original test (Schilling, 1953) was used to assess absorption of vitamin $B_{12}$ from the gut.

The urinary excretion of ${ }^{58} \mathrm{Co}$-vitamin $\mathrm{B}_{12}$ following an oral dose of $1 \mu \mathrm{g}$. was measured. Carbachol $0.25 \mathrm{mg}$. was given by subcutaneous injection at the same time as the oral vitamin $\mathrm{B}_{12}$, and an intramuscular injection of $1,000 \mu \mathrm{g}$. of nonradioactive vitamin $B_{12}$ was given two hours later. Urine was collected for 24 hours. In this laboratory $12-30 \%$ of the oral dose is found in the 24-hour urine collection in normal subjects.

\section{Clinical Findings}

The ages of the 55 patients ( 53 women, 2 men) ranged from 31 to 84 years (mean 58.3). Except for the three with symptomless webs dysphagia had been present for periods varying from a few months to over 30 years. The approximate age of onset is given in Table $\mathrm{I}$.

\begin{tabular}{l|c|c|c|c|c|c|c}
\multicolumn{7}{c}{ TABLE I.-Age at Onset of Dysphagia } \\
\hline $\begin{array}{l}\text { Age in years } \\
\text { No. cf cases }\end{array}$ & 220 & $\begin{array}{c}20-29 \\
6\end{array}$ & $\begin{array}{c}30-39 \\
7\end{array}$ & $\begin{array}{c}40-49 \\
14\end{array}$ & $\begin{array}{c}50-59 \\
12\end{array}$ & $\begin{array}{c}60-69 \\
10\end{array}$ & $\begin{array}{c}70+ \\
1\end{array}$ \\
\hline
\end{tabular}

The group of 36 patients in whom dysphagia was the primary complaint included 23 who said they had been anaemic in the past and six who said anaemia was in the family. Seventeen of these patients had a smooth or sore tongue, and 20 either complained of brittle finger-nails or had koilonychia on examination. Among the 16 in whom dysphagia was a secondary feature nine complained of past anaemia and four gave a family history of anaemia. Ten of these patients had a smooth or sore tongue and 13 had koilonychia or brittle nails. Only one of the three patients with symptomless webs said she had been anaemic in the past.

Physical examination revealed slight but definite thyroid enlargement in 19 patients. This was not of a degree normally 
causing dysphagia. Three other patients had had a thyroidectomy in the past. Of these, one had been for a carcinoma of the thyroid a year previously, and this patient was subsequently found to have a post-cricoid carcinoma. Another post-thyroidectomy patient was later found to have a carcinoma of the stomach. Two patients had had a gastrectomy in the past-one a total gastrectomy for a gastric carcinoma and the other a partial gastrectomy for peptic ulceration.

Barium swallow examination was carried out in all cases. Of the 36 patients whose dysphagia was the presenting symptom 21 had post-cricoid webs, including five with two webs ; 10 had an upper oesophageal stricture, of which five were found to be malignant on biopsy; and five had no radiological abnormality in this region. Of the 16 patients in whom dysphagia was a secondary symptom 14 were found to have a post-cricoid web, and one of these also had a benign stricture in the upper oesophagus. Two patients in this group had no radiological abnormality. One of the patients with primary dysphagia had a carcinoma at the lower end of the oesophagus and another had a hiatus hernia. Neither of these had a postcricoid lesion.

The type of lesion in the post-cricoid region shows some relation to the duration of symptoms (Table II). Carcinomatous change was found only in those who had complained of dysphagia for more than 20 years.

TABLE II.-Type of Lesion in Relation to Duration of Dysphagia

\begin{tabular}{|c|c|c|c|c|c|c|}
\hline \multirow{2}{*}{\multicolumn{3}{|c|}{$\begin{array}{l}\text { Duration of } \\
\text { Dysphagia }\end{array}$}} & \multicolumn{4}{|c|}{ No. of Cases with } \\
\hline & & & \multirow{2}{*}{$\begin{array}{r}\text { Web } \\
3 \\
2 \\
12 \\
7 \\
7 \\
7\end{array}$} & \multirow{2}{*}{$\begin{array}{c}\begin{array}{c}\text { Benign } \\
\text { Stricture }\end{array} \\
- \\
- \\
\overline{2} \\
2 \\
2\end{array}$} & \multirow{2}{*}{$\frac{\text { Carcinoma }}{\bar{E}}$} & \multirow{2}{*}{$\begin{array}{c}\begin{array}{c}\text { No } \\
\text { Lesion }\end{array} \\
- \\
2 \\
3 \\
1 \\
1 \\
-\end{array}$} \\
\hline $\begin{array}{l}\text { No dysphagia } \\
<1 \text { year } \\
1-5 \text { years } \\
6-10 \text { ", } \\
11-20 \text { ", } \\
\text { Over } 20 ",\end{array}$ & $\begin{array}{l}\ldots \\
\cdots \\
\cdots \\
\cdots\end{array}$ & $\begin{array}{l}\ldots \\
\cdots \\
\cdots \\
\cdots \\
\cdots\end{array}$ & & & & \\
\hline Total & & $\ldots$ & 38 & 6 & 5 & 7 \\
\hline
\end{tabular}

Two of the patients in this series were mother and daughter. Two other daughters in this family were seen, and both said they had always been anaemic and had taken iron in the past ; one of these had a hypochromic anaemia at the time of examination but no other symptoms. Another patient said that her mother had died from cancer of the throat. A detailed family history was not taken in the other patients.

\section{Laboratory Findings}

Blood Picture.-The haemoglobin ( $\mathrm{Hb}$ ) concentration in each case and mean corpuscular haemoglobin concentration (M.C.H.C.) in 53 cases are indicated in Fig. 1. Women with a haemoglobin concentration of $12 \mathrm{~g} . / 100 \mathrm{ml}$. or less were regarded as anaemic. The 29 patients anaemic by this criterion include the 14 in whom this was the primary complaint. This group also included both the men studied. The M.C.H.C. was less than the normal value of $32-36 \%$ in 27 patients, 11 of these having presented with anaemia.

Serum iron concentration was measured in 54 patients and was found to be abnormally low (less than $80 \mu \mathrm{g} . / 100 \mathrm{ml}$.) in 36 patients, including 12 whose complaint was anaemia. The total iron-binding capacity of the serum was measured in 39 patients, in 23 of whom it was raised above the normal upper limit of $400 \mu \mathrm{g} . / 100 \mathrm{ml}$. (Fig. 2). This includes eight patients with anaemia as the primary complaint.

Serum Vitamin $B_{12}$. - The results of this assay carried out in 45 patients are shown in Fig. 3. They are normal except in three patients from whom values of 30,63 , and $95 \mu \mu \mathrm{g} . / \mathrm{ml}$. were obtained. These three showed megaloblastic haemopoiesis: one had had a partial gastrectomy 12 years previously for peptic ulcer and had been complaining of intermittent dysphagia for two years ; the other two presented with symptoms of anaemia together with dysphagia, and proved to be cases of pernicious anaemia.

Tubeless gastric analysis was carried out in 48 patients and showed achlorhydria in 37 (Fig. 4).

Schilling Test.-This investigation was carried out on all 55 patients, with the results shown in Fig. 4. Twenty-seven had a urinary excretion of vitamin $\mathrm{B}_{12}$ below the normal limit for this test and 13 excreted only $6 \%$ or less of the oral dose. This last group included two patients who had had gastrectomies. Tubeless test meals carried out on the other 11 patients in this group showed that all of them had achlorhydria. Only four patients in this group had come to hospital because of anaemia.

Fig. 5 shows the relation between serum vitamin- $B_{12}$ concentration and the results of the Schilling test. Although vitamin- $B_{12}$ concentrations less than $200 \mu \mu \mathrm{g} . / \mathrm{ml}$. were associated with evidence of subnormal vitamin- $\mathrm{B}_{12}$ absorption, some of the cases with low results in the Schilling test had normal serum concentrations. This may be due to persistence

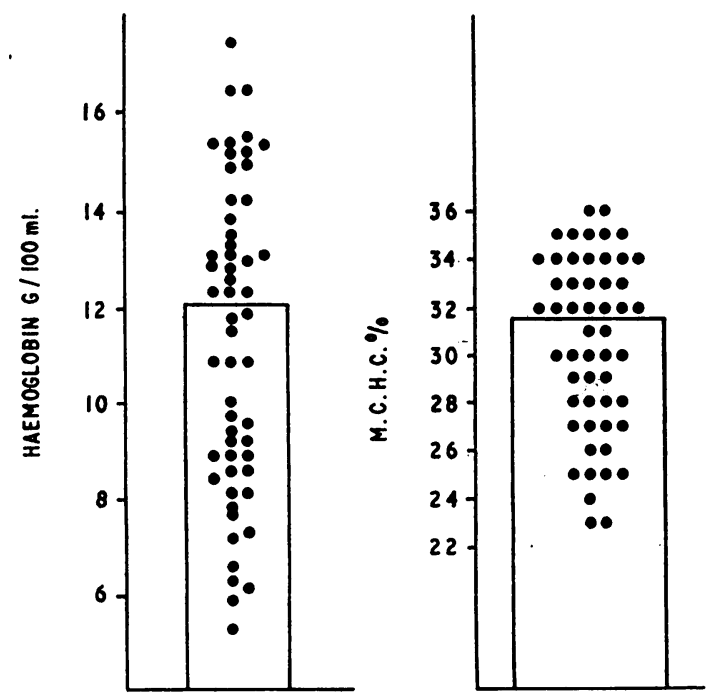

FIG. 1.- Haemoglobin concentration and mean corpuscular haemoglobin concentration. The enclosed areas are outside the normal range of values.
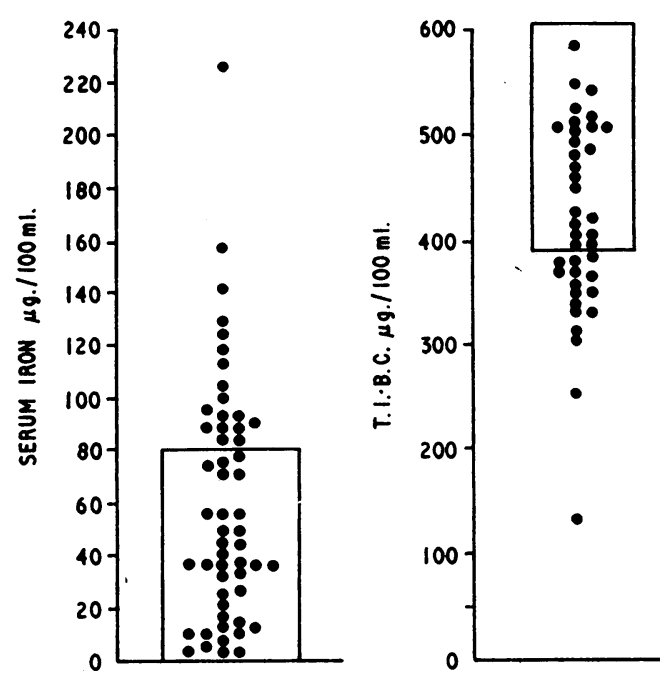

FIG. 2.-Serum iron concentration and total iron-binding capacity. The enclosed areas are outside the normal range of values.

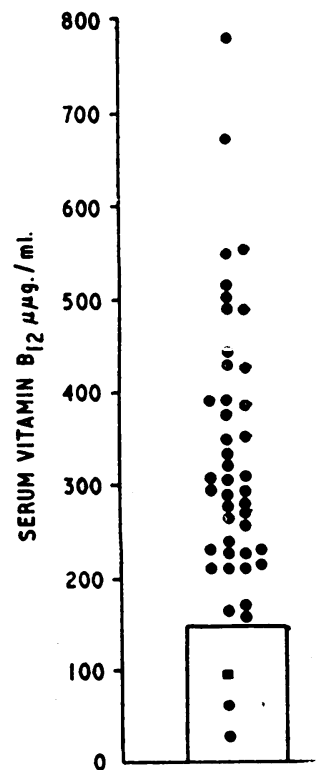

FIG. 3.-Serum vitamin$\mathrm{B}_{12}$ concentration. The enclosed area is outside the normal range of values. 
of vitamin- $\mathrm{B}_{1,}$, stores in the body in some patients, but the influence of occasional injections of vitamin $B_{12}$ outside hospital cannot always be cxcluded.

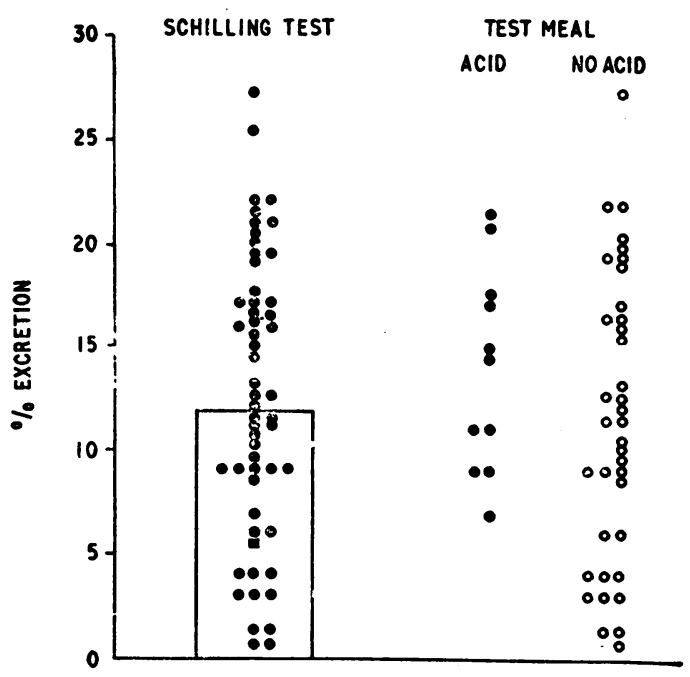

FIG. 4.-Schilling test and tubeless test meal. The e.zclosed area is outside the normal range of values. The test-meal result for each patient is placed at the same level as the result of her Schilling test.

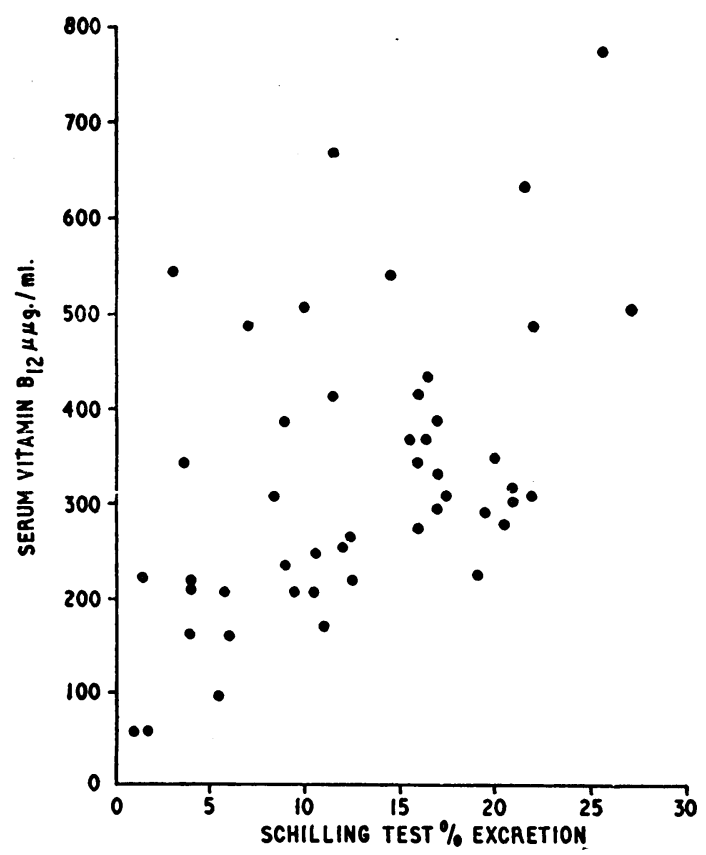

FIG. 5.-Serum vitamin- $B_{12}$ concentration plotted against urinary excretion of vitamin $\mathrm{B}_{1}$, in a Schilling test on the same patient.

In six patients where results of the Schilling test were subnormal the test was repeated, giving $50 \mathrm{mg}$. of an intrinsicfactor preparation (supplied by Lederle Laboratories) together with the oral dose of vitamin $B_{12}$. In three cases absorption of the vitamin was increased in the way normally seen in pernicious anaemia. In the other three cases there was no significant change in the results of the test. One of the latter patients was discovered to have a carcinoma of the stomach with widespread metastases at the time of the second test.

\section{Discussion}

The association between dysphagia in the post-cricoid region and iron-deficiency anaemia has led to the view that iron deficiency is the fundamental defect. However, the response of dysphagia to treatment with iron is ambiguous. Some immediate improvement may occur, but even when this happens the radiological abnormalities usually remain unchanged. The recurrence of symptoms after surgical dilatation of the lesion is not influenced by iron therapy. Kirchenberger and Flett (1946) found relapses occurring both in those patients treated with iron and in those who had had none. They doubted the necessity of continued treatment with iron other than for the correction of anaenia. McNab Jones (1961) also found dysphagia to recur in some patients who had been taking iron continuously.

Half the patients in the present investigation were anaemic ; in nearly all instances this was due to iron deficiency. One man with megaloblastic haemopoiesis had a post-gastrectomy anaemia with haemoglobin 8.5 g. $/ 100 \mathrm{ml}$, M.C.H.C. $25 \%$, serum iron $6 \mu \mathrm{g} . / 100 \mathrm{ml}$, , and total iron-binding capacity $592 \mu \mathrm{g} . / 100 \mathrm{ml}$. His serum vitamin-B $\mathrm{B}_{12}$ content was $95 \mu \mu \mathrm{g} . / \mathrm{ml}$. Two other patients with megaloblastic haemopoiesis and low serum vitamin- $\mathrm{B}_{12}$ levels were found to be classical cases of Addisonian pernicious anaemia with serum iron concentrations of 55 and $113 \mu \mathrm{g} . / 100 \mathrm{ml}$. The M.C.H.C. was low in 27 anaemic patients, but a low serum iron was found in 36, indicating that iron deficiency without anaemia may have been present in some patients.

These findings confirm previous observations of an association between iron deficiency and the Paterson-Kelly syndrome. The proportion of anaemic patients is similar to that found by Wynder and Fryer (1958) using the same criterion in their series of 121 women, but they found only $48 \%$ of their patients to have serum iron levels below $90 \mu \mathrm{g} . / 100 \mathrm{ml}$. Wynder and Fryer comment on objections to the view that iron deficiency is the sole aetiological factor in this condition. Thus, not only did over half their patients have no evidence of sideropenia but $23 \%$ denied ever having been anaemic. Of our 55 patients, 21 similarly denied having had anaemia. A more important objection is the rarity of this syndrome in some populations where severe chronic iron deficiency is common. Trowell (1960) and Jacobs (1963) have pointed out that the clinical picture described by Paterson and Kelly is an extreme rarity in East and Central Africa despite the almost universal prevalence of iron deficiency in some areas. The syndrome appears to be especially common among Northern Europeans, and it seems probable that environmental or constitutional factors play a part in determining the efforts of iron deficiency.

The association of achlorhydria with the Paterson-Kelly syndrome has been known almost as long as the syndrome itself (Moersch and Conner, 1926). In the present investigation 37 out of 48 cases had achlorhydria demonstrated by tubeless gastric analysis with maximum histamine stimulation. Recent studies suggest that most of these patients have atrophic gastritis or gastric atrophy (Correia and de Moura, 1963 ; Bock, Richards, and Witts, 1963). This is a lesion almost invariably found in pernicious anaemia (Joske, Finckhe, and Wood, 1955). It is found also in iron-deficiency anaemia, and in the patients investigated by Badenoch, Evans, and Richards (1957) dysphagia was a symptom only in the group with severe gastric atrophy; 4 out of 20 patients showed impaired absorption of vitamin $\mathrm{B}_{12}$. Mollin, Booth, and Baker (1957) suggested that the malabsorption occurring with simple gastric atrophy was corrected when an injection of carbachol was given together with the oral vitamin $B_{12}$. This was thought to be due to stimulation of intrinsic-factor secretion, which did not occur in cases of pernicious anaemia.

In the present investigation 25 patients (excluding those having had gastric surgery) showed evidence of subnormal absorption of vitamin $B_{12}$, and in 11 patients this was of a degree usually associated with pernicious anaemia. All these $11 \mathrm{had}$ achlo:hydria. Two of them were overt cases of pernicious anaemia with megaloblastic haemopoiesis, and the others 
appear to fall into the transitional state, the early stage of which has been described as pre-pernicious anaemia and the later stage as latent pernicious anaemia (Wood, Cowling, Ungar, and Gray, 1960).

The evolution of gastric atrophy to latent pernicious anaemia has been described by Wood et al. (1960), but it is not known whether gastric atrophy invariably progresses to this stage. The transformation of latent into clinical pernicious anaemia is believed to depend on the individual's body stores of vitamin $B_{12}$ and on external precipitating factors, such as infection. The fact that achlorhydria was so often found in those of our patients whose absorption of vitamin $B_{12}$ was normal suggests that the patients with latent pernicious anaemia may have had a pre-existing simple atrophic gastritis.

The significance of gastric atrophy in iron-deficiency anaemia is not certain. It has been held that the gastric mucosal changes are the result of iron deficiency (Davidson and Markson, 1955 ; Badenoch et al., 1957). Against this view is the rarity of achlorhydria in the chronic iron-deficiency anaemia of hookworm infestation (Foy and Kondi, 1960 ; Ball, personal communication) and the finding that gastric atrophy, when it does occur, is not reversed by the administration of iron (Lees and Rosenthal, 1958).

Coghill (1960) has shown that atrophic gastritis is more common in those patients with iron-deficiency anaemia in whom there is no evidence either of blood loss or of exceptionally deficient iron intake. This "idiopathic" gastric atrophy appears to be genetically determined. It is most common in the Northern European races and rare in equatorial Africa. It is often a prelude to the development of pernicious anaemia. The combination of iron deficiency and the PatersonKelly syndrome is not found in a population unaffected by gastric atrophy. In patients with gastric atrophy, however, the Paterson-Kelly syndrome may appear either before there is any anaemia or after the gastric atrophy has led to the development of latent pernicious anaemia or iron-deficiency anaemia. Dysphagia may occur in patients with uncomplicated pernicious anaemia, so that iron deficiency does not appear to be essential to its development.

\section{Summary}

An investigation of 55 cases of the Paterson-Kelly syndrome showed a high incidence of iron deficiency, achlorhydria, and subnormal vitamin- $\mathrm{B}_{12}$ absorption.

It is suggested that this syndrome is associated with the genetically determined gastric atrophy found in patients with pernicious anaemia and that iron deficiency is a secondary feature.

We are indebted to the staff of the Cardiff Royal Infirmary, who have allowed us to investigate patients under their care, and to Professor H. Scarborough for his helpful criticism. One of us (A. J.) is in receipt of a grant from the Endowment Fund of the United Cardiff Hospitals.

\section{REFERENCES}

Ahlbom, H. E. (1936). Brit. med. F., 2, 331.

Badenoch, J., Evans, J. R., and Richards, W. C. D. (1957). Brit. 3. Haemat., 3, 175 .

Bock, O. A. A., Richards, W. C. D., and Witts, L. J. (1963). Gut, 4, 112. Coghill, N. F. (1960). Postgrad. med. f., 36, 733 .

Correia, J. P., and de Moura, M. C. (1963). Brit. med. F., 1, 365

Correia, J. P., and de Moura, M. C. (1963). Brit. med. F., 1, 365.

Dacie, J. V. (1956). Practical Haematology, 2nd ed. Churchill, Lon

Foy, H., and Kondi, A. (1960). Trans. roy. Soc. trop. Med. Hyg., 54, 419.

Jacobs, A. (1962). Brit. med. f., 2, 91.

(1963). Ibid., 1, 1711 .

Joske, R. A., Finckh, E. S., and Wood, I. J. (1955). Quart. F. Med., 24,

Kelly, A. B. (1919). F. Laryng., 34, 285.

Kirchenberger, W., and Flett, R. L. (1946). Ibid., 61, 396.

Lees, F., and Rosenthal, F. D. (1958). Quart. F. Med., 27, 19.

McNab Jones, R. F. (1961). f. Laryng., 75, 529.

Moersch, H. J., and Conner, H. M. (1926). Arch. Otolaryng., 4, 112.

Mollin, D. L., Booth, C. C., and Baker, S. J. (1957). Brit. F. Haemut.. 3,412 .

Paterson, D. R. (1919). f. Laryng., 34, 289.

Ramsay, W. N. M. (1957). Clin. chim. Acta, 2, 214.

Schilling, R. F. (1953). f. Lab. clin. Med., 42, 860.

Smiley, T. B., McDowell, R. F. C., and Costello, W. T. (1963). Lance!, 2,7 .

Trowell, H. C. (1960). Non-infective Disease in Africa. Arnold, London. Vinson, P. P. (1922). Minn. Med., 5, 107.

Waldenström, J., and Hallen, L. (1938). Acta med. scand., Suppl. No. 90. p. 380 .

Witts, L. J. (1931). Guy's Hosp. Rep., 81, 193.

Wood, I. J., Cowling, D. C., Ungar, B., and Gray, A. (1960). Aust. Ann. Med., 9, 309.

Wynder, E. L., and Fryer, J. H. (1958). Ann. intern. Med., 49, 1106.

\title{
Aetiology of Acute Hemiplegia in Childhood
}

\author{
EDWIN R. BICKERSTAFF,* M.D., M.R.C.P.
}

[With Special Plate]

Brit. med F., 1964, 2, 82-87

"Acute infantile hemiplegia of obscure aetiology" is a clearly defined clinical syndrome, well documented and easily recognizable. This ease has perhaps been too great; for by the use of this title, which is purely descriptive, one may be misled into thinking that a firm clinical diagnosis has been made. Attempts have been made in recent years to correct this, and it has also been appreciated that the syndrome is by no means confined to infants. The tendency now is to use the term "acute hemiplegia in childhood," which has expanded the scope of the diagnosis without clarifying its nature. Unfortunately it has allowed the inclusion of a number of different conditions which have only one feature in common-their * The Midland Centre for Neurosurgery and Neurology, Smethwick.
Birmingham. capacity for producing a hemiplegia in a child. Therefore, when any investigation is undertaken, be it clinical or pathological, it is essential for a clear statement to be made of the type of syndrome under consideration and the type of case to be admitted to the investigation.

\section{Clinical Syndrome}

The essential feature of the syndrome is the sudden development of a hemiplegia in a child hitherto neurologically and cardiologically normal. This therefore excludes all cases of maldevelopment, of birth trauma, of post-natal trauma, of embolism secondary to rheumatic endocarditis or congenital heart disease, and, of course, tumours, abscesses, etc. 